\title{
Does the Fukushima NPP disaster affect the caesium activity of North Atlantic Ocean fish?
}

\author{
G. Kanisch and M.-O. Aust \\ Thünen Institute of Fisheries Ecology, Marckmannstraße 129b, 20539 Hamburg, Germany
}

Correspondence to: G. Kanisch (guenter.kanisch@ti.bund.de)

Received: 18 December 2012 - Published in Biogeosciences Discuss.: 5 March 2013

Revised: 30 June 2013 - Accepted: 8 July 2013 - Published: 13 August 2013

\begin{abstract}
Fillet samples of marine fish collected from the East/West Greenland currents (GC) and from the Baltic Sea (BS) have been investigated by gamma-ray spectrometry within the regular German monitoring programme. In samples of the second half of $2011,{ }^{134} \mathrm{Cs}$ traces have been detected that are suggested to originate from the Fukushima fallout that was deposited in March/April 2011 over the northern North Atlantic and accumulated by fish. The radionuclide ${ }^{134} \mathrm{Cs}$ (half-life $2 \mathrm{yr}$ ) was indeed detected with quite small activities at about $0.0036 \mathrm{~Bq} \mathrm{~kg}^{-1}$ w.w. Existing box models describing the transport of $\mathrm{Cs}$ within seawater boxes of the northeast Atlantic allowed for estimation of ${ }^{134} \mathrm{Cs}$ contributions from other sources, i.e. from the Chernobyl fallout and from discharges by the two major European nuclear reprocessing plants; both were negligible around Greenland, while for the Chernobyl fallout a small ${ }^{134} \mathrm{Cs}$ background contribution to BS fish was estimated. Model results confirmed the level of ${ }^{134} \mathrm{C}$ measured in BS fish and showed its maximum to have occurred in winter 2011/2012 followed by a continuous decrease. It was also determined that ${ }^{134} \mathrm{Cs}$ activity, but not that of ${ }^{137} \mathrm{Cs}$, showed a significant negative correlation with sampling depth (150$400 \mathrm{~m}$ ) of GC fish; this strengthens our Fukushima fallout assumption. As a result, the Fukushima fallout in these sea areas only marginally enhanced (GC: $4 \%$; BS: $0.1 \%$ ) preFukushima levels of individual dose rates received by human fish consumers; the addition was around $0.001 \mu \mathrm{Sv}$ following the consumption of $10 \mathrm{~kg}$ of fish per year, which is not expected to cause concern according to present guidelines for radiation protection.
\end{abstract}

\section{Introduction}

On 11 March 2011, a Tsunami hit the Fukushima Daiichi nuclear power plant (FD-NPP), which caused the loss of cooling capacity in four of its six nuclear reactors and led to the release of radionuclides into the environment. It was expected that between 6 and $47 \mathrm{PBq}\left(1 \mathrm{PBq}=10^{15} \mathrm{~Bq}\right)$ of ${ }^{137} \mathrm{Cs}$ (half-life $30.17 \mathrm{yr}$ ) was directly discharged into the $\mathrm{Pa}-$ cific Ocean (e.g. Bailly du Bois et al., 2012) in the aftermath of the tragedy. More recent publications using more detailed data estimated amounts between 4 and $6 \mathrm{PBq}^{137} \mathrm{Cs}$ leaked into the Pacific Ocean (Povinec et al., 2013; Miyazawa et al., 2013; Estournel et al., 2012). Due to the determined ${ }^{134} \mathrm{Cs} /{ }^{137} \mathrm{Cs}$ ratio of around 1 , about the same amount of ${ }^{134} \mathrm{Cs}$ (half-life $2.07 \mathrm{yr}$ ) was discharged into the Pacific. Initially, discharge was assumed to represent the larger fraction of total Cs releases. Therefore, many researchers and TEPCO have focussed on the determination and estimation of the behaviour of Cs in Pacific waters and its behaviour in the environment, especially the uptake by biota (e.g. Buesseler et al., 2011, 2012; Honda et al., 2012; Madigan et al., 2012; Behrens et al., 2012).

The explosions of units 1 to 4 of FD-NPP also released radionuclides into the atmosphere, with an amount of about 12 to $15 \mathrm{PBq}$ for each of ${ }^{137} \mathrm{Cs}$ and ${ }^{134} \mathrm{Cs}$, respectively (Povinec et al., 2013; Estournel et al., 2012); this was detectable around the world (e.g. Hsu et al., 2012; Stohl et al. 2012; Jakobs, 2011). From these investigations the wet and dry deposition of caesium isotopes in marine areas where German monitoring was carried out after the accident at FD-NPP occurred - the North Sea, the Baltic Sea (BS), and the coastal West and East GCs - were estimated to be between 0.1 and $100 \mathrm{~Bq} \mathrm{~m}^{-2}$. 


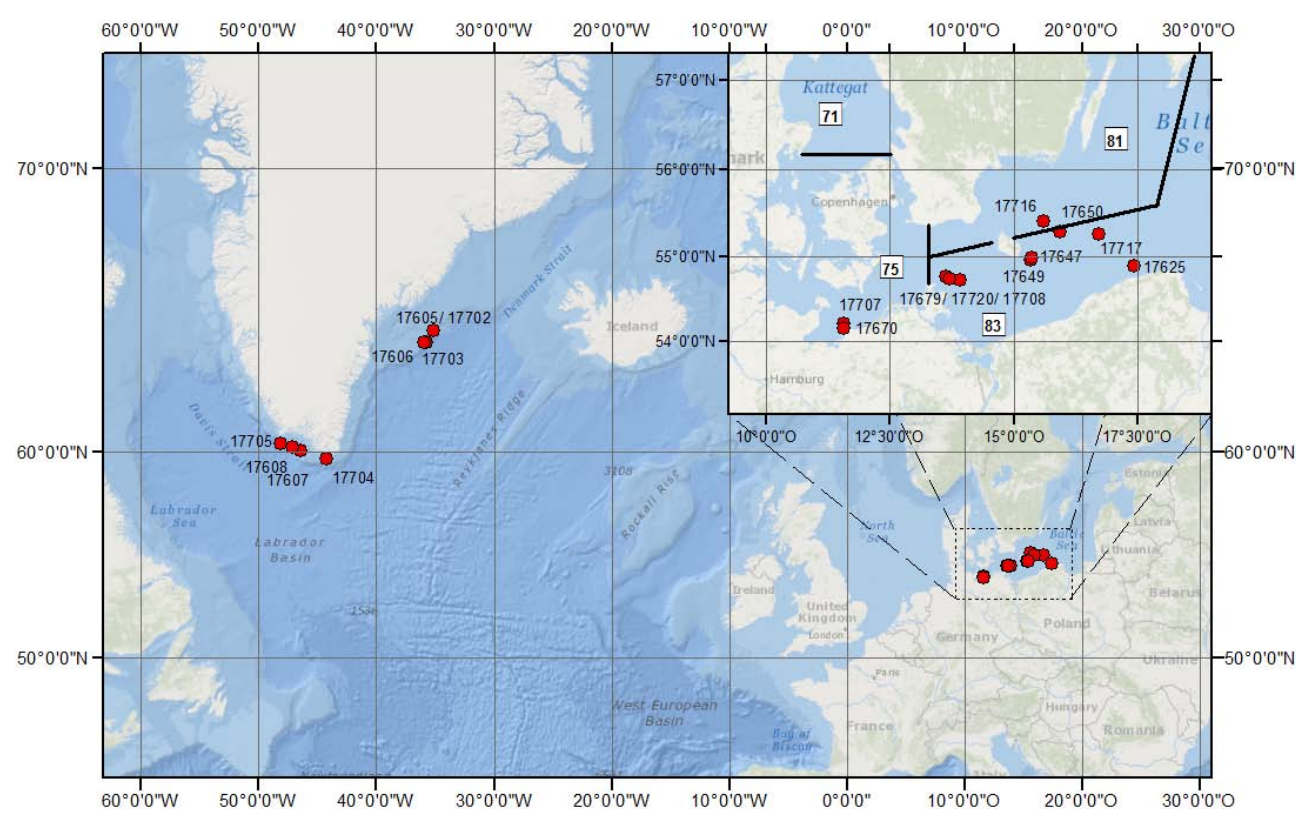

Fig. 1. Sites for sampling of cod, redfish and whiting (see Table 1 for sample details) for analysis of radioactivity in the Labrador Basin and the BS (scale of the large map is $1: 42.000 .000$; scale of the small map is $1: 10.000 .000$ ). The small map of the BS contains the borders and nomenclature of the water boxes (numbers in boxes: $71=$ Kattegat, surface; $75=$ Belt Sea, surface; $81=$ BS west, surface; $83=$ BS east, surface) for estimation of the Cs behaviour using the modified HELCOM box model (see HELCOM, 1995, or Kanisch et al., 2000, for details).

The deposition of Fukushima fallout radionuclides occurred during the last week in March 2011 until about the beginning of May 2011. An average deposition of $2 \mathrm{~Bq} \mathrm{~m}^{-2}$ for each of ${ }^{134} \mathrm{Cs}$ and ${ }^{137} \mathrm{Cs}$ was measured at three locations in Denmark by Ris $\varnothing$ DTU (Nielsen, 2011). Furthermore, in Finland, depositions of $1.75 \mathrm{~Bq} \mathrm{~m}^{-2}$ for each of ${ }^{134} \mathrm{Cs}$ and ${ }^{137}$ Cs was measured by STUK in Helsinki (Ikäheimonen, 2011) during 21 April and 14 May in 2011 using 1-week sample periods. From Greenland, to the best of our knowledge, no such determinations are available.

Putting FD-NPP deposition estimates and the resulting concentrations measured in Greenland into perspective, they are comparable with those of the Chernobyl accident in the Baltic Sea (BS), which was characterized by a mean deposition of $12000 \mathrm{~Bq}^{137} \mathrm{Cs} \mathrm{m}^{-2}$, and led to an activity concentration between 50 and $5200 \mathrm{~Bq} \mathrm{~m}^{-3}$ in seawater and up to $270 \mathrm{~Bq}^{137} \mathrm{Cs} \mathrm{kg}^{-1}$ wet weight (w.w.) in fish (HELCOM, 1995). The resulting concentration factors of up to $400 \mathrm{imply}$ that fish is the most reasonable test organism for monitoring of the input of caesium isotopes from FD-NPP into different oceans and the separation of FD-NPP from historic Cs inputs, namely through global fallout and the catastrophe at Chernobyl nuclear power plant.

From this point of view, the aims of our study were (i) to determine the activity concentration of caesium isotopes in cod and redfish as economically relevant fish species in the North Atlantic Ocean and its marginal seas, (ii) to separate the FD-NPP input from that from Chernobyl and global fall- out and (iii) to validate the determinations and estimate the future behaviour of caesium isotopes in fish of the BS using the first-order kinetics box model previously developed within a HELCOM Working Group MORS-EG to model Chernobyl ${ }^{137} \mathrm{Cs}$ in seawater and fish of the BS.

\section{Materials and methods}

\subsection{Sampling and sample preparation}

Biota were caught during research and monitoring cruises using the RV Walther Herwig III carried out between October 2010 and December 2011 using bottom trawls or collected from commercial catches from trawlers operating within ICES (International Council for the Exploration of the Sea) subdivisions in the BS. Sampling positions are indicated in Fig. 1. Round fish samples selected from the catches, consisting of 2 to 31 individual animals (Table 1), were stored at $-20^{\circ} \mathrm{C}$ after sampling of $5 \mathrm{~kg}$ small fish or $15 \mathrm{~kg}$ larger fish. Larger fishes (especially cod) were filleted on board before freezing. The dry mass of the samples was determined in the laboratory by drying at $110^{\circ} \mathrm{C}$ for 2 days. Afterwards, dried samples were dry-ashed at a maximum temperature of $420^{\circ} \mathrm{C}$. The retrieved ash, which was between 50 and $70 \mathrm{~g}$, was homogenized and transferred to $200 \mathrm{~mL}$ cylindrical PVC containers for gamma spectrometric analysis, resulting in variable filling heights and bulk densities of about 25$40 \mathrm{~mm}$ and $0.44-0.56 \mathrm{~g} \mathrm{~cm}^{-3}$, respectively. The fish samples 
Table 1. Characterization of fish samples (cod: Gadus morhua; redfish: Sebastes marinus; whiting: Merlangius merlangius)

\begin{tabular}{|c|c|c|c|c|c|c|c|c|c|c|}
\hline $\begin{array}{l}\text { sample } \\
\text { ID }\end{array}$ & $\begin{array}{l}\text { sampling } \\
\text { date }\end{array}$ & species & $\begin{array}{c}\text { depth } \\
\text { of catch } \\
\text { m }\end{array}$ & $\begin{array}{c}\text { average fish } \\
\text { weight } \\
\text { kg }\end{array}$ & $\begin{array}{c}\text { average fish } \\
\text { length } \\
\mathrm{cm}\end{array}$ & $\begin{array}{c}\text { \# of } \\
\text { specimen } \\
\text { kg }\end{array}$ & $\begin{array}{c}\text { wet sample } \\
\text { mass (fillets) }\end{array}$ & $\begin{array}{c}\text { mass ratio } \\
\text { wet/dry } \\
\mathrm{g}\end{array}$ & $\begin{array}{c}\text { ash } \\
\text { mass } \\
\mathrm{h}\end{array}$ & $\begin{array}{l}\text { counting } \\
\text { duration }\end{array}$ \\
\hline \multicolumn{11}{|c|}{ Greenland } \\
\hline 17605 & 15 Oct 2010 & redfish & 394 & 6.04 & 67 & 2 & 3.03 & 3.26 & 34.58 & 160 \\
\hline 17606 & 27 Oct 2010 & $\operatorname{cod}$ & 291 & 5.54 & 86 & 2 & 2.70 & 5.11 & 40.35 & 160 \\
\hline 17607 & 25 Oct 2010 & $\operatorname{cod}$ & 417 & 3.32 & 84 & 2 & 3.25 & 4.75 & 45.67 & 160 \\
\hline 17608 & 25 Oct 2010 & redfish & 156 & 5.59 & 56 & 2 & 1.64 & 3.93 & 20.08 & 160 \\
\hline 17702 & 21 Oct 2011 & redfish & 375 & 1.38 & 50 & 6 & 3.99 & 3.75 & 50.66 & 410 \\
\hline 17703 & 21 Oct 2011 & cod & 339 & 6.0 & 82 & 4 & 4.52 & 5.02 & 67.91 & 390 \\
\hline 17704 & 29 Oct 2011 & cod & 144 & 7.3 & 92 & 4 & 4.14 & 4.86 & 57.11 & 390 \\
\hline 17705 & 30 Oct 2011 & redfish & 243 & 1.78 & 50 & 6 & 4.09 & 3.98 & 53.66 & 390 \\
\hline \multicolumn{11}{|c|}{ Baltic Sea } \\
\hline 17649 & 5 May 2011 & $\operatorname{cod}$ & 78 & 0.95 & 44 & 17 & 3.07 & 5.31 & 39.13 & 320 \\
\hline 17650 & 5 May 2011 & cod & 78 & 1.77 & 55 & 13 & 4.31 & 5.28 & 56.60 & 320 \\
\hline 17707 & 4 Dec 2011 & cod & 22 & 3.22 & 66 & 7 & 3.69 & 4.37 & 49.98 & 320 \\
\hline 17708 & 5 Dec 2011 & whiting & 33 & 0.75 & 42 & 31 & 5.33 & 4.16 & 66.29 & 368 \\
\hline 17716 & 12 Dec 2011 & $\operatorname{cod}$ & 50 & 0.87 & 46 & 25 & 4.36 & 5.48 & 54.21 & 394 \\
\hline 17717 & 13 Dec 2011 & $\operatorname{cod}$ & 92 & 0.94 & 47 & 26 & 4.11 & 5.41 & 50.29 & 394 \\
\hline \multicolumn{11}{|c|}{ Baltic Sea, from screening } \\
\hline 17647 & 19 Apr 2011 & $\operatorname{cod}$ & 70 & 0.73 & 40 & 22 & 3.04 & 5.39 & 38.60 & 160 \\
\hline 17670 & 18 Sep 2011 & $\operatorname{cod}$ & 4 & 1.11 & 48 & 15 & 3.69 & 5.40 & 48.57 & 160 \\
\hline 17679 & 4 Sep 2011 & $\operatorname{cod}$ & 45 & 0.81 & 43 & 27 & 5.00 & 5.23 & 66.18 & 160 \\
\hline 17720 & 14 Dec 2011 & $\operatorname{cod}$ & 42 & 1.01 & 46 & 26 & 5.56 & 4.93 & 76.29 & 160 \\
\hline
\end{tabular}

selected for this investigation are characterized in Table 1. Fish age was not determined.

\subsection{Gamma-ray spectrometric analysis}

\subsubsection{Spectrometry basics}

For the analysis of gamma-emitting radionuclides three highpurity germanium detectors $(2 \times$ n-type; $1 \times$ p-type $)$ with relative efficiencies between 36 and $55 \%$ and energy resolutions of around $1.9 \mathrm{keV}$, both at $1.33 \mathrm{MeV}$. The detectors are protected against environmental radiation by standard lowlevel lead shieldings of $10 \mathrm{~cm}$ lead and inner layers of copper, cadmium and Plexiglas. Two multi-channel analyser (MCA) modules were used for recording the spectra with 4096 channels. The MCA spectra were transferred into an external spectrum database used by the GamW software for spectrum evaluation, which is an in-house development. Some details of the spectrum analysis techniques used in this program are given in Appendix A, in which also some measures for improving the detection of ${ }^{134} \mathrm{Cs}$ are described. Radionuclide activity is always referred to in wet weight (w.w.).

The full-energy peak efficiency curves were re-calibrated in January 2011 using a liquid multi-radionuclide standard solution 7503ML (Eckert \& Ziegler, Braunschweig, Germany; 11 radionuclides including ${ }^{210} \mathrm{~Pb}$ and ${ }^{241} \mathrm{Am}$ ) covering the energy range of 46 to $1836 \mathrm{keV}$; relative standard uncertainties of the activity concentrations were about $1 \%$. Two-dimensional efficiency curves, depending on gamma energy and filling height in the container were fitted to the measured efficiency data for four heights between 12 and $56 \mathrm{~mm})$. Calculations of true coincidence summing corrections (TCS) were included during efficiency curve fitting; see Appendix A for more information about TCS corrections.

The standard counting durations for screening on caesium isotopes was $160 \mathrm{~h}$. When there was some evidence of the presence of ${ }^{134} \mathrm{Cs}$, the measurements of those samples were prolonged to $320-410 \mathrm{~h}$ for improving the counting statistics and lowering the detection limit. The ISO 11929 decision threshold was used as a criterion for the detection of ${ }^{134} \mathrm{Cs}$ (see Appendix A for details).

\subsubsection{Quality control}

The stability of the detection efficiencies is controlled by counting every few weeks a ${ }^{152} \mathrm{Eu}$ point source on the detectors. The detector background is measured two times a year by collecting two or three 1-week spectra; the peak net counting rates are evaluated statistically, also by comparing the results with those of the sum spectra obtained by summing up these 2-3 spectra per detector. For external quality control the lab participates in national (Federal Office for Radiation Protection (BfS), Berlin, Germany; water samples) as well as IAEA-EL intercomparison exercises with marine 
origin samples. The latest IAEA intercomparison test sample measured with the new calibration from January 2011 was a seaweed sample (code IAEA-446). Our results for mean activity concentrations (i.e. activities per unit mass) of ${ }^{40} \mathrm{~K}$ and ${ }^{137} \mathrm{Cs}$ differed only $1.1 \%$ from the preliminary IAEA reference values (under evaluation). More information about the intercomparison exercises our lab participated in, as well as about GamW built-in utilities for routinely testing evaluations of complex spectra, can be found in HELCOM (2012).

\subsection{Modelling $\mathrm{Cs}$ in fish}

For validation of the activity concentrations for ${ }^{134} \mathrm{Cs}$ and ${ }^{137} \mathrm{Cs}$ measured in BS fish and giving an estimation of the future behaviour of the Cs isotopes in fish, the HELCOM box model for the BS case has been used (HELCOM, 1995; Kanisch et al., 2000). In this compartment model, the BS and the North Sea are separated into several water boxes in which the transport of radionuclides between water boxes, sorption and remobilization of radionuclides to/from the sediment, the physical decay of radionuclides and the input from anthropogenic sources is described by first-order differential equations. Modelling results have recently been presented in a HELCOM Thematic Assessment Report (HELCOM, 2009); see also Nielsen et al. (2010). The model takes timedependent uptake by biota into account. For the special case of the fallout deposited to the BS, it has been extended to a two-compartment model by considering piscivorous fish (or predatory fish in the following) feeding on smaller fish (food fish). We refer to Rowan and Rasmussen (1996, 1997), as well as Smith (2006), Fievet and Plet (2003) and Wang et al. (2000), for the underlying bioenergetics-based assumptions. A direct uptake of Cs from seawater has been included according to Brown et al. (2006). The link between the model's seawater activity concentrations, $c_{\mathrm{w}}(t)$ in $\mathrm{BqL}^{-1}$, and the activity concentrations in food fish and the predating fish, $c_{\mathrm{fd}}(t)$ and $c_{\mathrm{F}}(t)$ in $\mathrm{Bq} \mathrm{kg}^{-1}$ w.w., respectively, is given by a system of two coupled first-order differential equations solved by a Runge-Kutta method (Press et al., 1992). Including specific growth of the predating fish, the equations are

$$
\begin{aligned}
\frac{\mathrm{d} c_{\mathrm{fd}}(t)}{\mathrm{d} t}= & K_{\mathrm{fd}}\left(\lambda_{\mathrm{bio}, \mathrm{fd}}+\lambda_{\mathrm{p}}\right) c_{\mathrm{w}}(t)+k_{\mathrm{w}} c_{\mathrm{w}}(t) \\
& -\left(\lambda_{\text {bio, fd }}+\lambda_{\mathrm{p}}\right) c_{\mathrm{fd}}(t),
\end{aligned}
$$

$$
\frac{\mathrm{d} c_{\mathrm{F}}(t)}{\mathrm{d} t}=k_{\mathrm{F}} \alpha c_{\mathrm{fd}}(t)+k_{\mathrm{w}} c_{\mathrm{W}}(t)-\left(\lambda_{\mathrm{bio}, \mathrm{F}}+\lambda_{\mathrm{p}}+\lambda_{\mathrm{G}}\right) c_{\mathrm{F}}(t),
$$

with rate constants $\lambda_{\mathrm{p}}, \lambda_{\text {bio,fd }}$ and $\lambda_{\text {bio, F }}\left(\mathrm{d}^{-1}\right)$ linked to the physical half-life of the radionuclide and the biological halflives of food and fish, respectively; $\lambda_{\mathrm{G}}$ is the specific growth rate $\left(\mathrm{g} \mathrm{g}^{-1} \mathrm{~d}^{-1}\right.$ or $\left.\% \mathrm{~d}^{-1}\right)$ of the predator fish; $K_{\mathrm{fd}}$ and $K_{\mathrm{F}}$ are the concentration factors of food and predator fish, respectively, in $\mathrm{L} \mathrm{kg}^{-1} ; \alpha$ is the food assimilation efficiency of the predator; for $k_{\mathrm{w}}$ denoting the uptake rate of Cs from water a value of $0.04 \mathrm{~d}^{-1}$ was used; $k_{\mathrm{F}}$ denotes the predating fish's rate of ingesting food $\left(\mathrm{g} \mathrm{g}^{-1} \mathrm{~d}^{-1}\right)$. The general relation between $T_{\text {bio }}$ and $\lambda_{\text {bio }}$ is $\lambda_{\text {bio }}=\ln 2 / T_{\text {bio }}$. An average value of $0.0015 \mathrm{~g} \mathrm{~g}^{-1} \mathrm{~d}^{-1}$ was estimated as $\lambda_{\mathrm{G}}$ for BS cod, with a typical (total) length of about $50 \mathrm{~cm}$, from the weight-based von Bertalanffy growth parameters, which are available in the FishBase database (Froese and Pauly, 2011).The quantities $k_{\mathrm{F}}$ and $\alpha$ can be eliminated by expressing by analogy the first term of Eq. (2) like that of Eq. (1) and taking the relation $c_{\mathrm{fd}}(t)=K_{\mathrm{fd}} c_{\mathrm{w}}(t)$ into account:

$k_{\mathrm{F}} \alpha K_{\mathrm{fd}}=K_{\mathrm{F}}\left(\lambda_{\text {bio, } \mathrm{F}}+\lambda_{\mathrm{p}}+\lambda_{\mathrm{G}}\right)$.

By implementing this in the model, assuming a single-time input to the Baltic seawater box surfaces, activity concentrations of fish were modelled by using a caesium concentration factor $K_{\mathrm{F}}$ of $164 \mathrm{~L} \mathrm{~kg}^{-1}$ (HELCOM, 2009; due to lower salinity in the BS it is larger than the value of $100 \mathrm{~L} \mathrm{~kg}^{-1}$ used otherwise for marine fish; IAEA, 2004a) and an assumed value of 150 days for the biological half-life $T_{\mathrm{bio}, \mathrm{F}}$ (corresponding to the rate constant of the Cs elimination from fish). For food fish (smaller fish), assumed values of $50 \mathrm{~L} \mathrm{~kg}^{-1}$ and 80 days were used for $K_{\text {fd }}$ and $T_{\text {bio, fd, }}$, respectively.

Brown et al. (2006) used in their simulation study a range of $T_{\text {bio, F }}$ from 69 to 385 days for marine fish and a "representative" value of $116 \mathrm{~d}$. We used a value of 100 days for modelling the behaviour of Sellafield-derived ${ }^{134} \mathrm{Cs}$ in GC fish with a single-fish-compartment version; this case can be considered as very close to a steady-state situation; thus a value more appropriate than 100 days is not considered necessary. We did not try to model the Fukushima-derived ${ }^{134} \mathrm{Cs}$ in Greenland fish, because we lack an appropriate sub-model describing how the ${ }^{134} \mathrm{Cs}$, deposited on the surface, would be mixed within the vertical water column. However, in the BS, with its significantly lower salinity compared to the Atlantic Ocean, the biological half-lives may be significantly larger for fresh-water fish than for pure marine fish (Rowan and Rasmussen, 1996, 1997). Therefore, a value of 150 days used for $T_{\mathrm{bio}, \mathrm{F}}$ in the BS is only a rough estimate.

The fish samples originating from the BS were collected from the water boxes 75, 81 and 83, which represent the Belt Sea and the Baltic Proper (Fig. 1). The water depths and the salinities are quite variable, with gradients from west to east: between about 30 and $160 \mathrm{~m}$ (depth), between 15 and $7.5 \mathrm{~m}$ (surface salinity) and between 20 and $8 \mathrm{~m}$ (bottom salinity) (HELCOM, 2010). Therefore, each of the three water boxes included a surface and a bottom layer; within the model, the surface layer thickness is about one-third of the total depth. For calculating the activities in fish, the modelled activity concentrations in seawater were averaged over the selected six box layers by weighting with their associated box-layer volumes. A value of $2 \mathrm{~Bq} \mathrm{~m}^{-2}$ (see introduction) for each of the caesium isotopes was used for the Fukushima fallout deposited to the BS surface boxes. 
Table 2. Decay-corrected activity concentrations $A$ of ${ }^{134} \mathrm{Cs},{ }^{137} \mathrm{Cs}$ and ${ }^{40} \mathrm{~K}$ and associated relative uncertainties $\left(u_{\text {rel }}\right)$ in fish fillet samples from the Greenland and BS sites; the decision threshold DT (not shown) is well approximated by the value DL/1.548; SF is a significance factor, i.e. the ratio A / DT; "non-detects" are documented as $<$ DL.

\begin{tabular}{|c|c|c|c|c|c|c|c|c|c|c|}
\hline \multirow[t]{3}{*}{ sample ID } & \multirow[t]{3}{*}{ species } & \multicolumn{5}{|c|}{${ }^{134} \mathrm{Cs}$} & \multicolumn{2}{|l|}{${ }^{137} \mathrm{Cs}$} & \multicolumn{2}{|l|}{${ }^{40} \mathrm{~K}$} \\
\hline & & $\begin{array}{r}\text { DetLim } \\
\text { (DL) }\end{array}$ & $A$ & $\begin{array}{r}\gamma \\
\text { lines }\end{array}$ & $u_{\mathrm{rel}}$ & SF & $A$ & $u_{\text {rel }}$ & $A$ & $u_{\text {rel }}$ \\
\hline & & $\mathrm{Bq} \mathrm{kg}^{-1}$ w.w. & & & $\%$ & & $\mathrm{~Bq} \mathrm{~kg}^{-1}$ w.w. & $\%$ & $\mathrm{~Bq} \mathrm{~kg}^{-1}$ w.w. & $\%$ \\
\hline \multicolumn{11}{|l|}{ Greenland } \\
\hline 17605 & redfish & 0.0072 & $<0.0072$ & 0 & & & 0.183 & 4.0 & 106 & 3.6 \\
\hline 17606 & $\operatorname{cod}$ & 0.0093 & $<0.0093$ & 0 & & & 0.209 & 4.1 & 136 & 3.6 \\
\hline 17607 & $\operatorname{cod}$ & 0.0062 & $<0.0062$ & 0 & & & 0.279 & 3.7 & 138 & 3.6 \\
\hline 17608 & redfish & 0.0100 & $<0.0100$ & 0 & & & 0.269 & 4.0 & 132 & 3.6 \\
\hline 17702 & redfish & 0.0032 & $<0.0032$ & 0 & & & 0.201 & 3.7 & 114 & 3.6 \\
\hline 17703 & $\operatorname{cod}$ & 0.0046 & 0.0027 & 1 & 35.6 & 0.91 & 0.216 & 3.8 & 127 & 3.6 \\
\hline 17704 & $\operatorname{cod}$ & 0.0036 & 0.0058 & 2 & 13.4 & 2.54 & 0.260 & 3.8 & 134 & 3.6 \\
\hline 17705 & redfish & 0.0028 & 0.0042 & 2 & 15.1 & 2.31 & 0.188 & 3.7 & 116 & 3.6 \\
\hline \multicolumn{11}{|l|}{ Baltic Sea } \\
\hline 17649 & $\operatorname{cod}$ & 0.0046 & 0.0039 & 1 & 24.2 & 1.35 & 6.72 & 3.6 & 130 & 3.6 \\
\hline 17650 & $\operatorname{cod}$ & 0.0063 & $<0.0063$ & 0 & & & 6.81 & 3.7 & 132 & 3.6 \\
\hline 17707 & $\operatorname{cod}$ & 0.0043 & 0.0037 & 2 & 23.7 & 1.37 & 6.51 & 3.8 & 136 & 3.6 \\
\hline 17708 & whiting & 0.0035 & 0.0026 & 1 & 27.8 & 1.16 & 7.30 & 3.6 & 117 & 3.6 \\
\hline 17716 & $\operatorname{cod}$ & 0.0051 & $<0.0051$ & 0 & & & 7.30 & 3.6 & 123 & 3.6 \\
\hline 17717 & $\operatorname{cod}$ & 0.0044 & $<0.0044$ & 0 & & & 7.00 & 3.7 & 124 & 3.6 \\
\hline \multicolumn{11}{|c|}{ Baltic Sea, from screening } \\
\hline 17647 & $\operatorname{cod}$ & 0.0083 & 0.0050 & 1 & 34.5 & 0.96 & 8.18 & 3.7 & 130 & 3.6 \\
\hline 17670 & $\operatorname{cod}$ & 0.0058 & 0.0042 & 1 & 28.6 & 1.13 & 4.29 & 3.6 & 131 & 3.6 \\
\hline 17679 & $\operatorname{cod}$ & 0.0055 & 0.0034 & 1 & 33.1 & 0.98 & 4.18 & 3.6 & 127 & 3.6 \\
\hline 17720 & $\operatorname{cod}$ & 0.0045 & 0.0035 & 2 & 26.0 & 1.24 & 4.81 & 3.6 & 135 & 3.6 \\
\hline
\end{tabular}

For the Greenland case, another box model was used which extends the HELCOM box model with respect to the seas in and around the Arctic (Nielsen et al., 1995); with regards to the BS, the results from this extended model agreed very well with results of the other model. The extended box model was used for clarifying possible ${ }^{134} \mathrm{Cs}$ background sources in the Greenland case. However, it was not used to model the short-term behaviour of deposited Fukushima ${ }^{134} \mathrm{Cs}$ in seawater and in fish around Greenland. If one were to do this anyway, it would lead to unrealistically small estimated concentrations in seawater and fish. This is caused by the compartment model's specific property of instantaneously perfectly mixing the analyte within the overall box volume. This means in the case of the Greenland boxes that complete mixing is assumed over a large depth of $330 \mathrm{~m}$ in the surface layer, while the surface boxes are shallower in the BS. In reality one would expect a decreasing vertical activity concentration profile after fresh deposition on the seawater surface.

\section{Results and discussion}

\subsection{Greenland seas - Cs-activity concentrations and source identification for fish}

The results of the Cs measurements of Greenland fish are given in Table 2. The ${ }^{137} \mathrm{Cs}$ activities showed a quite similar distribution pattern of four samples each between 2010 and 2011. It is found that ${ }^{134} \mathrm{Cs}$ was clearly detected in the two 2011 fish samples (17704 and 17705) collected at the end of October 2011 in the West GC with ISO 11929-related significance factors $\mathrm{SF}>2.3 \gg 1$; $\mathrm{SF}$ is the ratio $\left({ }^{134} \mathrm{Cs}\right.$ activity) / $\left({ }^{134} \mathrm{Cs}\right.$ decision threshold $)$, the latter being calculated according to ISO 11929. The activity concentrations found, around $0.005 \mathrm{~Bq} \mathrm{~kg}^{-1}$, are extremely low. In contrast, in the two fish samples from the East GC (17702 and 17703), ${ }^{134} \mathrm{Cs}$ was about two times smaller and thereby hardly detectable, $\mathrm{SF}<1$. The activity ratio ${ }^{134} \mathrm{Cs} /{ }^{137} \mathrm{Cs}$ was about 0.013 for sample 17703 , while it showed the identical value of 0.022 for the two West GC samples. As the ${ }^{134} \mathrm{Cs} /{ }^{137} \mathrm{Cs}$ ratio of FD-NPP depositions was described to be close to 1 , the FD-NPP-derived ${ }^{137} \mathrm{Cs}$ must also be expected in fish of 
the same size for ${ }^{134} \mathrm{Cs}$. Therefore, for the two West GC samples of 2011 , the ratio ${ }^{137} \mathrm{Cs}^{\mathrm{Fuku}} /{ }^{137} \mathrm{Cs}$ pre-Fuku $={ }^{134} \mathrm{Cs}^{\mathrm{Fuku}} /$ ${ }^{137} \mathrm{Cs}^{\text {measured }}-{ }^{134} \mathrm{Cs}{ }^{\text {Fuku }}$ is about 0.023 , which means that the Fukushima deposition added at most about $2 \%$ to the existing pre-Fukushima ${ }^{137} \mathrm{Cs}$ in the West GC, while it was about or less than $1 \%$ in the East GC samples. Whether the surface seawater activity concentrations in the two regions were significantly different cannot be deduced, because due to other sampling strategy reasons, the fish were sampled in stratified layers; average depths were about around $200 \mathrm{~m}$ and about $400 \mathrm{~m}$ in the West Greenland and East Greenland site, respectively (see Table 1). For the rather fresh fallout situation the Cs isotopes with FD-NPP origin are not fully mixed over depths down to nearly $400 \mathrm{~m}$; therefore, the difference of ${ }^{134} \mathrm{Cs}$ values in fish between the two sites may simply be a consequence of different sampling/water depths when we assume that the fish stay for a longer time in these layers. The ${ }^{134} \mathrm{Cs}$ and ${ }^{137} \mathrm{Cs}$ values of fish were plotted versus sampling depth (Fig. 4). This reveals that the depth dependence of ${ }^{137} \mathrm{Cs}$ is rather weak, which means that slight ${ }^{137} \mathrm{Cs}$ differences found between the two sampling sites probably do not depend on sampling depth. However, the sampling depth dependency is quite strong for ${ }^{134} \mathrm{Cs}$. Thus, this observed sampling depth dependency, showing an incomplete vertical mixing of ${ }^{134} \mathrm{Cs}$ in the water column, supports our assumption that ${ }^{134} \mathrm{Cs}$ originates from the deposition of FDNPP fallout.

For the coastal East GC, Dahlgaard et al. (2004) found surface ${ }^{137} \mathrm{Cs}$ concentrations of about $3-4 \mathrm{~Bq} \mathrm{~m}^{-3}$ in 2001 ; they measured concentrations decreasing from 5 to $2.4 \mathrm{~Bq} \mathrm{~m}^{-3}$ in this Current, from north to south in the eastern branch and in the coastal West GC up to the north again. They also determined ${ }^{137} \mathrm{Cs}$ in two fish samples collected in 1999 in the East GC with values of 0.35 and $0.47 \mathrm{~Bq} \mathrm{~kg}^{-1}$ w.w. After decay correction with an effective half-life of $18.6 \mathrm{yr}$, by which the ${ }^{137} \mathrm{Cs}$ concentration in the North Atlantic seawater and in fish decreases (IAEA, 2005; according to data for the box 28 given therein), their average then amounts to $0.27 \mathrm{~Bq} \mathrm{~kg}^{-1}$ in 2010. This is rather close to our 2010 and 2011 averages of about $0.20 \mathrm{~Bq} \mathrm{~kg}^{-1}$ (from Table 2) for the two sites in the East GC. Extrapolating a ${ }^{137} \mathrm{Cs}$ seawater time trend for the corresponding water box number 28 taken from IAEA (2005) and using a concentration factor of $100 \mathrm{~L} \mathrm{~kg}^{-1}$ leads to a value of around $0.2 \mathrm{~Bq} \mathrm{~kg}^{-1}$ in fish. Our samples from the West GC show only slightly larger values of about $0.25 \mathrm{~Bq} \mathrm{~kg}^{-1}$.

Dahlgaard (1995) estimated a transport time of 7-10 yr of such discharges to the East GC. For testing possible contributions of the Sellafield-derived ${ }^{134} \mathrm{Cs}$ background to our measurements in fish, the box model extended with respect to the Arctic Sea (see Sect. 2.3) was used. ${ }^{137} \mathrm{Cs}$ values around $0.1 \mathrm{~Bq} \mathrm{~kg}^{-1}$ were obtained from this model using the surface layer (thickness $330 \mathrm{~m}$ ) of the relatively large box "Irminger Sea" and a fish concentration factor of $100 \mathrm{~L} \mathrm{~kg}^{-1}$. This is only 2.5 times lower than our measured values, i.e. not un- realistic. However, the corresponding values modelled for ${ }^{134} \mathrm{Cs}$ in fish, around $4 \times 10^{-6} \mathrm{~Bq} \mathrm{~kg}^{-1}$, were 1000 times below our measured ${ }^{134} \mathrm{Cs}$ values. This finding assures us that the ${ }^{134} \mathrm{Cs}$ measured in fish originates from the FD-NPP fallout deposition. Due to reasons similar to those given at the end of Sect. 2.3, but also because the Chernobyl Cs deposition $\left(\mathrm{Bq} \mathrm{m}^{-2}\right)$ to the $\mathrm{GC}$ is assumed to be much smaller than in the BS, it can be assumed that Chernobyl-derived ${ }^{134} \mathrm{Cs}$ in fish around Greenland would be much smaller than that estimated by modelling in the BS, and therefore would not contribute to the measured ${ }^{134} \mathrm{Cs}$ values.

\subsection{Baltic Sea - Cs-activity concentrations and source identification for fish}

Compared to the seas around Greenland with larger water flows, the rate of BS water exchange with the adjacent North Sea is rather small. In the Baltic the salinities therefore are lower due to freshwater inflows. The Chernobyl ${ }^{137} \mathrm{Cs}$ seawater inventory in the southern part of the BS (Baltic Proper) is decreasing, with an effective half-life of around $15 \mathrm{yr}$ (HELCOM, 2009).

Results of measurements are included in Table 2; the samples from the additional retrospective screening of many other spectra for the existence of ${ }^{134} \mathrm{Cs}$ are included. In the $\mathrm{BS}$, due to the impact of the Chernobyl fallout, the ${ }^{137} \mathrm{Cs}$ activity concentrations in fish are around $7 \mathrm{~Bq} \mathrm{~kg}^{-1}$, which is about 35 times larger than in the GCs. ${ }^{134} \mathrm{Cs}$ was found in only three of the six samples with larger counting durations. The ISO 11929-related significance factors SF of the ${ }^{134} \mathrm{Cs}$ values where closer to 1 , with about 1.36 at maximum, but for the other samples at around or even below 1. Thus, when including the four values from screening values, ${ }^{134} \mathrm{Cs}$ was definitely detected in only $50 \%$ of the samples. Therefore, methods for left-censored data (Helsel and Cohn, 1988; Helsel, 2005) were applied for obtaining descriptive statistics; mean and median values were about $0.0036 \mathrm{~Bq} \mathrm{~kg}^{-1}$. The BS model was used for clarifying the origin of ${ }^{134} \mathrm{Cs}$. Figures 2 and 3 show the curves modelled in fish and measured values of ${ }^{137} \mathrm{Cs}$ and ${ }^{134} \mathrm{Cs}$, respectively. The lower and upper boundary (dashed) curves $( \pm 2 \mathrm{~s})$ were calculated from the standard deviation of the six individual box activity concentrations.

It had been tested how setting up the fish kinetic sub-model affects the shape of the modelled curve of ${ }^{134} \mathrm{Cs}$. Within the curves (Fig. 3), mainly their increasing part and the height of the maximum were found to be more variable, while the decrease following the maximum is determined by the decrease of modelled ${ }^{134} \mathrm{Cs}$ in seawater (near equilibrium between water and fish). Lowering the biological half-life as well as adding specific fish growth to the single-compartment sub-model resulted in a steeper increase of the ${ }^{134} \mathrm{Cs}$ activity concentration before reaching the maximum. Introducing the food fish compartment has the effect of some delay in this increase. Figure 3 shows the results of two model 


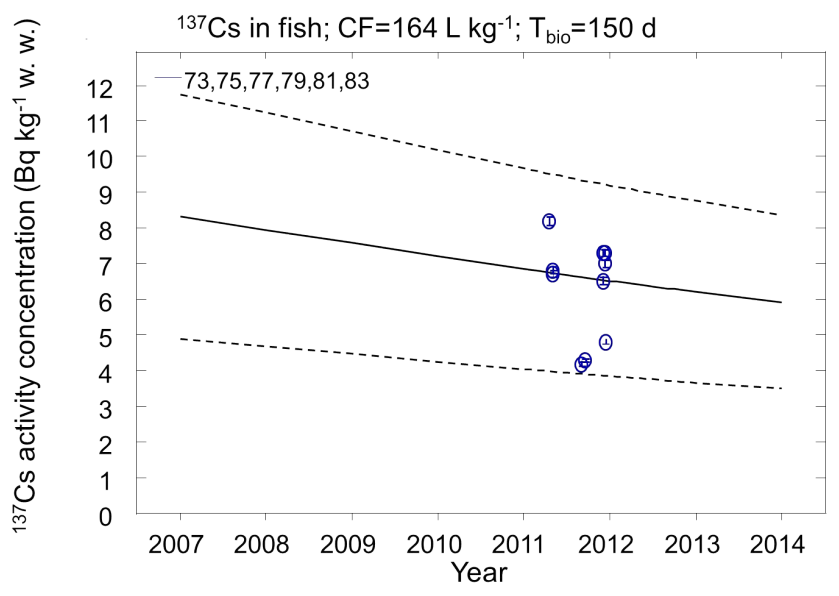

Fig. 2. Curves of ${ }^{137} \mathrm{Cs}$ activity per unit mass in fish using the twocompartment fish model, volume-averaged over the surface boxes 75,81 and 83 and their associated bottom-layer boxes, and measured values (circles) of ${ }^{137} \mathrm{Cs}$ in BS fish. Individual measured values are given with $\pm 2 \sigma$ bars; the dashed lines represent the $95 \%$ confidence curves of the model (see text).

variants: (i) a single-compartment model neglecting specific growth and Cs intake from water (upper graph), and a (ii) two-compartment model taking both of these effects into account (lower graph). Therefore, the result obtained with a simple single-compartment sub-model is considered reasonable taken as a first guess.

The model curve for ${ }^{137} \mathrm{Cs}$ in fish, which is mainly caused by the still large contribution of ${ }^{137} \mathrm{Cs}$ deposited during the Chernobyl accident, is unaffected by the FD-NPP deposition; the increase is as small as the line thickness in Fig. 2a. For ${ }^{134} \mathrm{Cs}$, however, the effect of FD-NPP fallout is clearly visible in the model, but with very low values of the order of $0.004 \mathrm{~Bq} \mathrm{~kg}^{-1}$ w.w., which is about 2000 times smaller than those of ${ }^{137} \mathrm{Cs}$. Note that the ${ }^{134} \mathrm{Cs}$ modelled for the preFD-NPP time is the one still originating from the Chernobyl accident; its activity continues to decrease with an effective half-live $t_{\text {eff }}$ of $1.9 \mathrm{yr}$ (calculated from the $t_{\text {eff }}$ value of $15 \mathrm{yr}$ for ${ }^{137} \mathrm{Cs}$; HELCOM, 2009). Additionally, it has been tested that possible ${ }^{134} \mathrm{Cs}$ contributions originating from small annual liquid discharges of the BS area nuclear power plants (see HELCOM, 2009, chapter (2)) would hardly be identifiable in the graph for ${ }^{134} \mathrm{Cs}$.

The good agreement between modelled and measured ${ }^{137} \mathrm{Cs}$ values suggests that the modelled ${ }^{134} \mathrm{Cs}$ values are as reliable as for ${ }^{137} \mathrm{Cs}$. As the two Cs isotopes have a different origin, one might argue that the very recently introduced ${ }^{134} \mathrm{Cs}$ behaves differently from ${ }^{137} \mathrm{Cs}$ with respect to mixing in the seawater. However, apart from one measured value from 19 April 2011, the measured ${ }^{134}$ Cs values from the post-Fukushima time are well within the lower and upper model boundaries (Fig. 2); this also holds for ${ }^{137} \mathrm{Cs}$. When continuing the upper ${ }^{134} \mathrm{Cs}$ boundary curve from the begin-
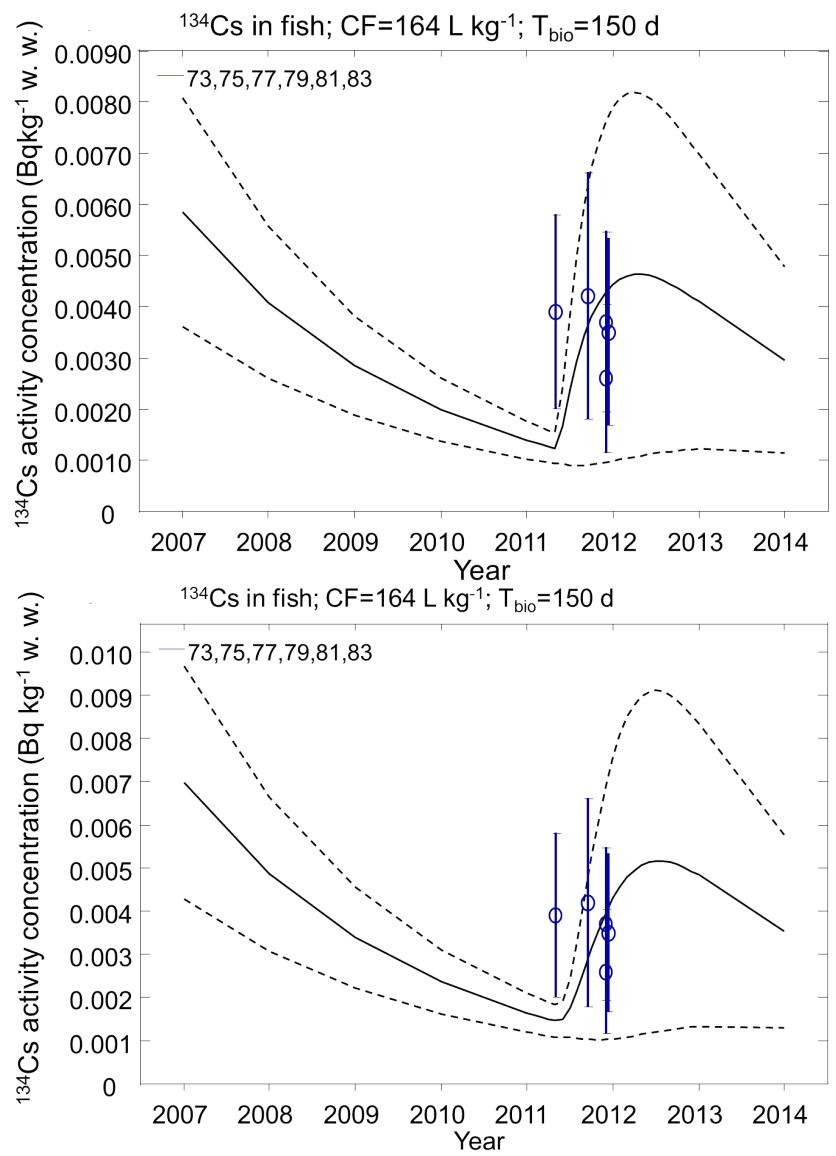

Fig. 3. Curves of ${ }^{134} \mathrm{Cs}$ activity per unit mass in fish using two models and measured values of ${ }^{134} \mathrm{Cs}$ in BS fish. Upper panel: singlecompartment model curves ignoring growth $G$ and Cs uptake from water $k_{\mathrm{W}}$. Lower panel: two-compartment model used with $G$ and $k_{\mathrm{W}}$ values given in the text, otherwise the same as in Fig. 2.

ning of 2011, i.e. when assuming no Fukushima input, this curve (pure Chernobyl ${ }^{134} \mathrm{Cs}$ ) during 2011 would also safely lie beneath the measured values. Therefore, we conclude that the major contribution to ${ }^{134} \mathrm{Cs}$ values measured in fish, on average about $0.0026 \mathrm{~Bq} \mathrm{~kg}^{-1}$, is related to the FD-NPP fallout deposition. The addition of ${ }^{137} \mathrm{Cs}$ from FD-NPP to existing ${ }^{137} \mathrm{Cs}$ in $\mathrm{BS}$ fish corresponds to an increase of only $0.04 \%$.

\subsection{Dose considerations about the Fukushima contribution}

The contribution of the FD-NPP fallout deposition to effective dose rates received by human individuals through consumption of fish is estimated in relation to the corresponding pre-FD-NPP dose rates. Assuming an annual human consumption of $10 \mathrm{~kg}$ of fish fillets and estimating the FD-NPP contribution from averages of measured ${ }^{134} \mathrm{Cs}$ values in fish using the activity ratio ${ }^{134} \mathrm{Cs} /{ }^{137} \mathrm{Cs}$ of about 1 in March 2011 (neglecting the ${ }^{134} \mathrm{Cs}$ decay), dose rate contributions 
Table 3. Average activity concentrations $\left(\mathrm{Bq} \mathrm{kg}^{-1}\right)$ and effective dose rate $\left(\mu \mathrm{Sv} \mathrm{yr}^{-1}\right)$ contributions to human individuals from consumption $\left(10 \mathrm{~kg} \mathrm{yr}^{-1}\right)$ of fish from 2011 ; dose conversion factors $\left(\mathrm{Sv} \mathrm{Bq}^{-1}\right)$ used were $1.9 \times 10^{-8}$ and $1.3 \times 10^{-8}$ for ${ }^{134} \mathrm{Cs}$ and ${ }^{137} \mathrm{Cs}$, respectively; note that ${ }^{134} \mathrm{Cs}^{\text {pre-Fukush }}$, not occurring in the table, can be neglected.

\begin{tabular}{lcccc}
\hline Radionuclide/Source & \multicolumn{2}{c}{ Greenland } & \multicolumn{2}{c}{ Baltic Sea } \\
& $\mathrm{Bq} \mathrm{kg}^{-1}$ & $\mu \mathrm{Sv} \mathrm{yr}$ & $\mathrm{Bq} \mathrm{kg}^{-1}$ & $\mu \mathrm{Sv} \mathrm{yr}^{-1}$ \\
\hline Fukushima & & & & \\
${ }^{134} \mathrm{Cs}$ Fukush & 0.0035 & $6.7 \mathrm{E}-04$ & 0.0026 & $4.9 \mathrm{E}-04$ \\
${ }^{137} \mathrm{Cs}$ Fukush $\approx{ }^{134} \mathrm{Cs}^{\text {Fukush }}$ & 0.0035 & $4.6 \mathrm{E}-04$ & 0.0026 & $3.4 \mathrm{E}-04$ \\
\hline Total F & & $1.1 \mathrm{E}-03$ & & $8.3 \mathrm{E}-04$ \\
\hline${ }^{137} \mathrm{Cs}$ measured: as measured & 0.21 & 0.027 & 6.8 & 0.88 \\
${ }^{137} \mathrm{Cs}$ pre-Fukush $=\left({ }^{137} \mathrm{Cs}^{\text {measured }}{ }^{137}{ }^{137} \mathrm{Cs}^{\text {Fukush }}\right)$ & 0.21 & 0.027 & 6.8 & 0.88 \\
dose rate ratio: total F/ ${ }^{137} \mathrm{Cs}^{\text {pre-Fukush }}=$ & & 0.042 & & 0.00094 \\
relative increase of the dose rate by Fukush. & & & & \\
\hline
\end{tabular}

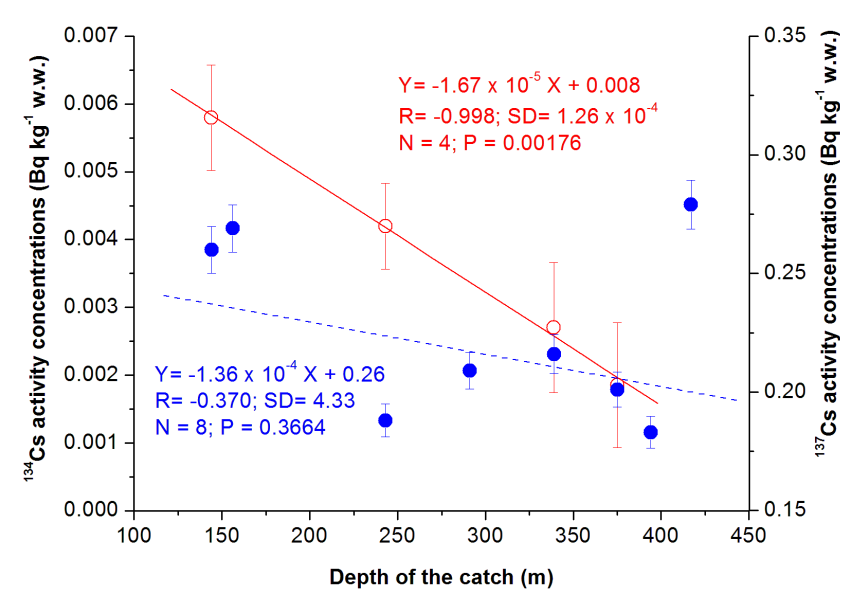

Fig. 4. Activity concentrations of ${ }^{134}$ Cs (open circles, left scale, 2011) and of ${ }^{137}$ Cs (closed circles, right scale, $2010+2011$ ) in fish fillets plotted versus sampling depth; measurement uncertainties given are $\pm 1 \sigma$; Note: the smallest of the ${ }^{134} \mathrm{Cs}$ values represents a "non-detect" with DL of 0.0032 , for which a replacement value was plotted.

to human individuals are obtained which are given in Table 3; the dose conversion coefficients (ICRP, 1996) are given in Table 3. The extremely low effective dose rates obtained for the Fukushima contribution were $0.0011 \mu \mathrm{Sv} \mathrm{y}^{-1}$ and $0.00083 \mu \mathrm{Sv} \mathrm{yr}^{-1}$ for the Greenland and BS areas, respectively. A main result is that the relative increase of the effective dose rate, caused by the deposition of Fukushima fallout, is about $4 \%$ for the Greenland case, but only about $0.1 \%$ in the BS case. The ${ }^{134} \mathrm{Cs}$ contribution will decrease from 2012 onwards (Fig. 3).

To put these extremely low dose rates into context they may be compared with those dose rates received by humans from the alpha-ray-emitting radionuclide ${ }^{210} \mathrm{Po}$, a naturally occurring radionuclide which is also accumulated by fish. From average ${ }^{210} \mathrm{Po}$ activities per unit mass of about
$0.94 \mathrm{~Bq} \mathrm{~kg}^{-1}$ w.w. in BS fish (HELCOM, 2009), a human fish consumer receives a dose of $11 \mu \mathrm{Sv}$ per year after consumption of $10 \mathrm{~kg}$ fish per year; a ${ }^{210} \mathrm{Po}$ dose conversion coefficient of $1.210^{-6} \mathrm{~Sv} \mathrm{~Bq}^{-1}$ has been considered (ICRP, 1996). In comparison, this dose rate is larger than that from the Fukushima contribution by more than a factor of $10^{4}$. The data in Table 3 also imply that even the dose rate received from Chernobyl-derived ${ }^{137} \mathrm{Cs}$ in BS cod $\left(0.88 \mu \mathrm{Sv} \mathrm{yr}^{-1}\right)$ is nearly 100-fold larger than that of the Fukushima contribution. Within a dose assessment for consumption of sea fish (Aarkrog et al., 1997), a ${ }^{210} \mathrm{Po}$ value in fish of $2.4 \mathrm{~Bq} \mathrm{~kg}^{-1}$ was used which, taking the meanwhile larger ICRP dose conversion coefficient into account, would result in a dose rate of $29 \mu \mathrm{Sv} \mathrm{yr}^{-1}$ for consuming $10 \mathrm{~kg}$ per year .

\section{Conclusions}

During our study, we determined caesium isotopes in fish samples from Greenland and the BS originating from FDNPP fallout deposited over the North Atlantic as suggested by other publications on modelling its airborne deposition. ${ }^{134} \mathrm{Cs}$ became detectable by using large amounts of fish fillets and an extended counting duration as compared to our standard method. In the Greenland Sea, which is much deeper compared to the BS, we observed a significant negative correlation $(p=0.0018)$ of ${ }^{134} \mathrm{Cs}$ activities in fish with sampling depths $(150-400 \mathrm{~m})$, while this was not true for ${ }^{137} \mathrm{Cs}$. This indicates that ${ }^{134} \mathrm{Cs}$ was not yet mixed in the water column which substantiates the Fukushima fallout as its origin, while a major part of ${ }^{137} \mathrm{Cs}$ originates from global fallout and is well mixed over this depth. It also indicates the general feature of ${ }^{134} \mathrm{Cs}$ as an ideal tracer that it is well suited for studying processes of vertical mixing of fallout in an ocean when the ${ }^{134} \mathrm{Cs}$ levels prior to the fallout are extremely low.

The additional contribution through FD-NPP fallout to the effective dose received by humans through consumption of fish was calculated to be extremely low, i.e. 4 orders of 
magnitude lower than the effective dose rate received at the same time by the naturally occurring ${ }^{210} \mathrm{Po}$, which is persistent in fish. Due to the short duration of deposition at sea, it is expected that levels of caesium isotopes from FD-NPP will continue to decrease in seawater by vertical and horizontal mixing and by physical decay. Therefore, our results indicate that, although based on a limited set of data, the improved monitoring of ${ }^{134} \mathrm{Cs}$ in fish, also in other northern areas such as the Barents Sea, in combination with the northeast Atlantic waters box model, are essential tools to maintain consumer safety.

\section{Appendix A}

\section{Details of gamma-ray spectrometric analysis with GamW}

A numerical procedure for geometry-dependent selfattenuation corrections, accounting also for different elemental compositions of fish ash and the calibration solution, is included in GamW. Calculated self-attenuation corrections at $605 \mathrm{keV}$ were between 0.91 and 0.94 .

The method used for the TCS calculations including Xray contributions was that of Novcović et al. (2007); see also Kanisch et al. (2009). The extension from point to volume sources was achieved by the "LS-curve" method (Vidmar and Korun, 2006; Vidmar and Kanisch, 2010; Lépy et al., 2012). Approximate total efficiency curves required by such calculations were obtained with the gamma-ray spectrometry simulation tool GESPECOR (Sima et al., 2001). The linear energy calibration is re-calculated for each sample spectrum according to well-known radionuclide energies in the spectrum. The spectrum evaluation then starts with a peak search followed by nuclide-library-based complementation of the list of peaks; peak multiplets are fitted by non-linear weighted least squares (Press et al., 1992; Levenberg-Marquardt subroutine MRQMIN). The peak shape function used (Koskelo et al., 1981) consists of a Gaussian function with low-energy tailing, extended by adding a step function to the 1-3 parameter background-continuum polynomial. The method described by Uher et al. (2010), which is in fact a penalized weighted least-squares method, was implemented into the MRQMIN package for stabilizing the fits, especially in the case of small peaks, which is achieved by adding a penalty term to the chi square to be minimized for the non-linear parameters (width, location, relative step height and the tailing parameter of a peak). Thus, such parameters are allowed to vary, thereby accounting for slight deviations from calibration values as they may occur during long-term measurements, and, on the other hand, they are prevented from leaving safe value domains, which guarantees convergence of the fit.

Net background peak counting rates are subtracted from the corresponding gross peak counting rates. Then, decay-
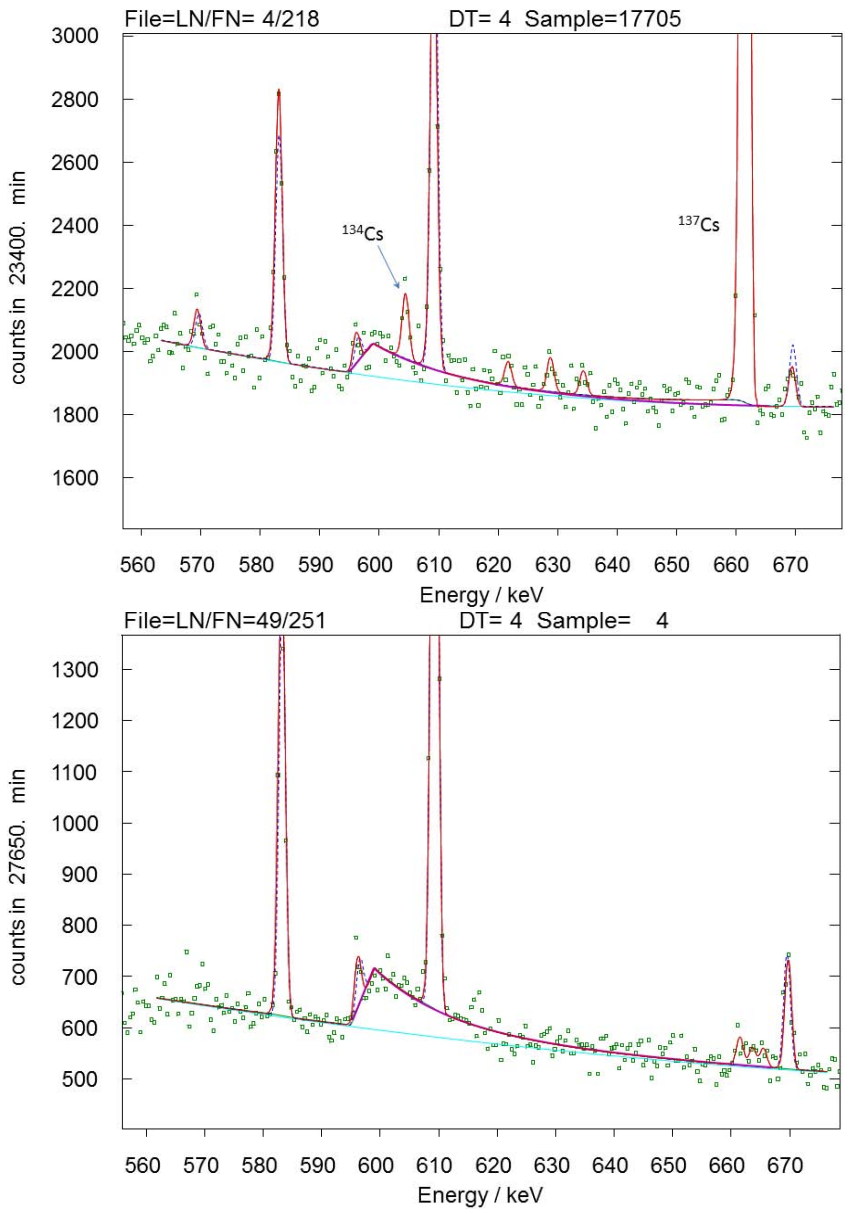

Fig. A1. Upper panel: ${ }^{134} \mathrm{Cs}$ (at $605 \mathrm{keV}$ ) and ${ }^{137} \mathrm{Cs}$ (at $662 \mathrm{keV}$ ) peaks fitted in the region $560-665 \mathrm{keV}\left(\chi_{R}^{2}=1.21\right)$; the red coloured curves show the peak fitting functions residing above a 3 parameter polynomial background continuum (light cyan); dashed peak curves indicate the peaks sizes obtained from separate background measurements. Note the broad neutron-induced background peak beneath the peaks of 605 and $609 \mathrm{keV}$; after accounting for different counting durations its fitted height parameter agrees to within $8 \%$ with that fitted in the separate background spectrum. The three small peaks between 609 and $662 \mathrm{keV}$ were found to be not significant. Lower panel: spectrum region of the corresponding background spectrum showing more clearly the neutron-induced background peak beneath and no ${ }^{134} \mathrm{Cs}$, respectively.

corrected massic radionuclide activities are calculated by solving a linear matrix equation system by the linear leastsquares method according to the standard ISO 11929 (2010; Annex C.5 therein) taking peak efficiency correlations into account (Glavic-Cindro et al., 2004). Major relative standard uncertainties were about $1.5 \%$ (peak efficiency around $662 \mathrm{keV}$ ), $2.9 \%$ (preparing the fish ash as counting source including the sample wet / dry weight ratio uncertainty), about $0.5 \%$ (gamma emission probabilities), $1 \%$ (self-attenuation corrections) and around $2 \%$ (TCS). 
Decision thresholds and detection limits were calculated for each sample measurement by applying the ISO 11929 concept to the matrix-based least-squares procedure; that is, not only for the easier-to-solve single-peak case of ${ }^{137} \mathrm{Cs}$ but also for ${ }^{134} \mathrm{Cs}$ for which one or two lines (at 604.8 and $796.0 \mathrm{keV}$ ) have been used; in the latter case the detection limit value is lower than for a single peak. Treating this by using a weighted mean rather than by least squares has been considered by Vivier et al. (2012). Values of $k_{1-\alpha}=3$ and $k_{1-\beta}=1.645$ were used for the quantiles of the normal distribution; the larger $k_{1-\alpha}$ value was used in order to prevent finding too many non-significant peaks (De Geer, 2004).

\section{A1 Special measures for improving the detection of ${ }^{134} \mathrm{Cs}$}

For reducing the uncertainty of the fitted areas of the background continuum polynomial, the multiplet regions of interest (ROI) around 605 and $796 \mathrm{keV}$ were extended to the ranges of about $560 \mathrm{keV}$ to $630 \mathrm{keV}$ and from $782 \mathrm{keV}$ to $825 \mathrm{keV}$, respectively; the first ROI often was enlarged to include also the ${ }^{137} \mathrm{Cs}$ peak at $661.7 \mathrm{keV}$. Peaks from naturally occurring radionuclides, also found in the separately measured background spectra, appeared at $609.3 \mathrm{keV}\left({ }^{214} \mathrm{Bi}\right)$ and at $794.9 \mathrm{keV}\left({ }^{228} \mathrm{Ac}\right)$, the latter lying quite close to the ${ }^{134} \mathrm{Cs}$ peak at $795.9 \mathrm{keV}$. Especially the spectra measured with the larger detector 4 showed more clearly an extra gamma-ray peak at around $596 \mathrm{keV}$ as well as an additional broad background continuum contribution with a slow exponential decay towards energies above about $620 \mathrm{keV}$. This is due to neutrons caused by cosmic ray interactions in the shielding materials, which then, by interactions within the detector, produce special gamma-ray peaks (e.g. at $596 \mathrm{keV}$ ), and, amongst others, this broad "neutron peak" above $596 \mathrm{keV}$ due to inelastic scattering with Ge (Heusser, 1995; Jovančević et al., 2010); it is much more easily recognized in background spectra in which the ${ }^{40} \mathrm{~K}$ related Compton background is much smaller than in fish ash samples. The functional representation of this "neutron-induced peak" given by Siiskonen and Toivonen (2005) has been implemented here in a simplified way as a further background component in the total fitting function. Figure A1 shows an example for the fitting region containing the 605 and $662 \mathrm{keV}$ peaks in the spectrum of sample 17705 (Greenland site).

The upper limit of relative standard uncertainties of single peaks entering the matrix equation mentioned above was raised to $50 \%$; however, according to ISO 11929 , final activity values were considered as being detected only if they were above the decision threshold. TCS corrections for ${ }^{134} \mathrm{Cs}$ being comparable between its two major lines were estimated at between about 14 and $24 \%$ for the three detectors. For the fish measurements, uncertainty budgets of activity concentrations (IAEA, 2004b) were dominated by contributions of sample preparation, peak efficiency and self-attenuation correction for ${ }^{40} \mathrm{~K}$ and ${ }^{137} \mathrm{Cs}$, while the counting rates contributed most dominantly in the case of ${ }^{134} \mathrm{Cs}$.

Acknowledgements. We are grateful for the valuable comments given by the reviewers $\mathrm{H}$. Nies and G. Pröhl and an anonymous reviewer, which significantly improved the quality of the paper. For the opportunities of receiving samples from RV Walther-Herwig III (Baltic Sea), from commercial Baltic Sea catches and for samples from around Greenland we thank our colleagues Thomas Lang, Joachim Dröse and Heino Fock from the Thünen Institute.

Edited by: H. Nies

\section{References}

Aarkrog, A., Baxter, M. S., Bettencourt, A.O., Bojanowski, R., Bologa, A., Charmasson, S., Cunha, I., Delfanti, R., Duran, E., Holm, E., Jeffree, R., Livingston, H. D., S. Mahapanyawong, S., Nies, H., Osvath,, I., Li Pingyu, Povinec, P. P., A. Sanchez, A., J. N. Smith, J. N., and Swift, D.: A Comparison of Doses from ${ }^{137}$ Cs and ${ }^{210}$ Po in Marine Food: A Major International Study, J. Environ. Radioactiv. 34, 69-90, 1997.

Bailly du Bois, P., Laguionie, P., Boust, D., Korsakissok, I., Didier, D., and Fiévet, B.: Estimation of marine source-term following Fukushima Dai-ichi accident, J. Environ. Radioactiv., 114, 2-9, doi:10.1016/j.jenvrad.2011.11.015, 2012.

Behrens, E., Schwarzkopf, F. U., Lübbecke, J. F., and Böning, C. W.: Model simulations on the long-term dispersal of ${ }^{137} \mathrm{Cs}$ released into the Pacific Ocean off Fukushima, Environ. Res. Lett. 7, 034004, doi:10.1088/1748-9326/7/3/034004, 2012.

Brown, J., Dowdall, M., Gwynn, J. P., Børretzen, P., Selnæs, Ø. G., Kovacs K. M., and Lydersen, C.: Probabilistic biokinetic modelling of radiocaesium uptake in Arctic seal species: verification of modelled data with empirical observations, J. Environ. Radioactiv., 88, 289-305, 2006.

Buesseler, K., Aoyama, M., and Fukasawa, M.: Impacts of the Fukushima nuclear power plants on marine radioactivity, Environ. Sci. Technol., 45, 9931-9935, 2011.

Buesseler, K.O., Jayne, S. R., Fisher, N. S., Rypina, I. I., Baumann, H., Baumann, Z., Breier, C. F., Douglass, E. M., George, J., Macdonald, A. M., Miyamoto, H., Nishikawa, J., Pike, S. M., and Yoshida, S.: Fukushima-derived radionuclides in the ocean and biota off Japan, P. Natl. Acad. Sci. USA, 109, 5984-5988, doi:10.1073/pnas.1120794109, 2012.

Dahlgaard, H.: Transfer of European Coastal Pollution to the Arctic: Radioactive Tracers, Mar. Pollut. Bull., 31, 3-7, 1995.

Dahlgaard, H., Eriksson, M., Nielsen, S. P., Joensen, H. P.: Levels and trends of radioactive contaminants in the Greenland environment, Sci. Total Environ., 331, 53-67, doi:10.1016/j.scitotenv.2004.03.023, 2004.

De Geer, L.-E.: Currie detection limits in gamma-ray spectroscopy, Appl. Radiat. Isotopes, 61, 151-160, doi:10.1016/j.apradiso.2004.03.037, 2004.

Estournel, C., Bosc, E., Bocquet, M., Ulses, C., Marsaleix, P., Winiarek, V., Osvath, I., Nguyen, C., Duhaut, T., Lyard, F., Michaud, H., and Auclair, F.: Assessment of the amount of Cesium-137 released into the Pacific Ocean after the Fukushima accident and analysis of its dispersion in Japanese coastal waters. 
J. Geophys. Res., 117, C11014, doi:10.1029/2012JC007933, 2012.

Fievet, B. and Plet, D.: Estimating biological half-lifes of radionuclides in marine compartments from environmental time-series measurements, J. Environ. Radioactiv., 65, 91-107, 2003.

Froese, R. and Pauly, D. (Eds): Fishbase, http://www.fishbase.org; Gadus morhua: http://www.fishbase.org/PopDyn/ PopGrowthList.php?ID=69\&GenusName $=$ Gadus $\&$ Speci, 2011.

Glavic-Cindro, D., Korun, M., and Vodenik, B.: Correlations between the activities of a gamma-ray emitter calculated from different peaks in the spectrum, Accredit. Qual. Assur., 9, 473-477, 2004.

Helsel, D.: Nondetects and Data Analysis: Statistics for Censored Environmental Data, John Wiley, New York, 2005.

Helsinki Commission (HELCOM): Baltic Marine Environment Protection Commission: Radioactivity in the Baltic Sea 19841991, Baltic Sea Environmental Proceedings No. 61, http://www. helcom.fi/stc/files/Publications/Proceedings/bsep61.pdf, 1995

Helsel, D. R. and Cohn, T. A.: Estimation of Descriptive Statistics for Multiply Censored Water Quality Data, Water Resour. Res., 24, 1997-2004, 1988.

Helsinki Commission (HELCOM): Radioactivity in the Baltic Sea, 1999-2006 - HELCOM thematic assessment, Baltic Sea Environmental Proceedings No. 117, http://www.helcom.fi/stc/files/ Publications/Proceedings/bsep117.pdf, Baltic Marine Environment Protection Commission, Helsinki, 2009.

Helsinki Commission (HELCOM): HELCOM Atlas of the Baltic Sea, Published by HELCOM, May 2010.

Helsinki Comission (HELCOM): Analytical Methods Used For Biological Samples for the HELCOM/MORS Group, Attached at the end (page 35) of: Guidelines for Monitoring of Radioactive Substances: http://www.helcom.fi/stc/files/Guidelines/ MORSGuidelines2011.pdf, 2012.

Heusser, G.: Low-Radioactivity Background Techniques, Ann. Rev. Nucl. Sci., 445, 543-590, 1995.

Honda, M. C., Aono, T., Aoyama, M., Hamajima, Y., Kawakami, H., Kitamura, M., Masumoto, Y., Miyazawa, Y., Takigawa, M., and Saino, T.: Dispersion of artificial caesium-134 and -137 in the western North Pacific one month after the Fukushima accident, Geochem. J., 46, e1-e9, 2012.

Hsu, S.-C., Huh, C.-A., Chan, C.-Y., Lin, S.-H., Lin, F.-J., and Liu, S. C.: Hemispheric dispersion of radioactive plume laced with fission nuclides from the Fukushima nuclear event, Geophys. Res. Lett., 39, L00G22, doi:10.1029/2011GL049986, 2012.

Ikäheimonen, T. K.: Deposition from Fukushima accident in Finland, http://meeting.helcom.fi/c/document_library/get_file?p_1_ $\mathrm{id}=16324 \&$ folderId=1438116\&name=DLFE-45402.pdf, 2011.

International Atomic Energy Agency (IAEA): Sediment Distribution Coefficients and Concentration Factors for Biota in the Marine Environment, Technical Reports Series No. 422, 2004a.

International Atomic Energy Agency (IAEA): Quantifying uncertainty in nuclear analytical measurements, IAEA-TECDOC1401, IAEA, Vienna, 2004b.

International Atomic Energy Agency (IAEA): Worldwide marine radioactivity studies (WOMARS) - Radionuclide levels in oceans and seas, IAEA-TECDOC-1429, IAEA, Vienna, 2005.

International Commission on Radiological Protection (ICRP): Agedependent doses to the members of the public from intake of ra- dionuclides: Part 5 Compilation of Ingestion and Inhalation Dose Coefficients, Publication 72, 1996.

ISO 11929: Determination of characteristic limits (decision threshold, detection limit, and limits of the confidence interval) for measurements of ionizing radiation - Fundamentals and applications, International Organization for Standardization, Geneva, 2010.

Jakobs, H.: Potential dispersion of the radioactive cloud over the Northern Hemisphere, http://www.eurad.uni-koeln.de/index_e. html, 2011.

Jovančević, N., Krmar, M., Mrda, D., Slivka, J., and Bikit, I.: Neutron induced background gamma activity in low-level Gespectroscopy systems, Nucl. Instrum. Meth. A, 612, 303-308, doi:10.1016/j.nima.2009.10.059, 2010.

Kanisch, G., Nagel, G., Krüger, A., and Kellermann, H.-J.: Radiological implications from the temporal development of radioactivity in marine food from the North Sea, Kerntechnik, 65, 183189, 2000.

Kanisch, G., Vidmar, T., and Sima, O.: Testing the equivalence of several algorithms for calculation of coincidence summing corrections, Appl. Radiat. Isotopes, 67, 1952-1956, doi:10.1016/j.apradiso.2009.07.002, 2009.

Koskelo, M. J., Aarnio, P. A., and Routti, J. T.: SAMPO80: An accurate gamma spectrum analysis method for minicomputers, Nucl. Instrum. Methods, 190, 89-99, 1981.

Lépy, M.-C., Altzitzoglou, T., Anagnostakis, M. J., Capogni, M., Ceccatelli, A., De Felice, P., Djurasevic, M., Dryak, P., Fazio, A., Ferreux, L., Giampaoli, A., Han, J. B., Hurtado, S., Kandic, A., Kanisch, G., Karfopoulos, K. L., Klemola, S., Kovar, P., Laubenstein, M., Lee, J. H., Lee, J. M., Lee, K. B., Pierre, S., Carvalhal, G., Sima, O., Chau Van Tao, Tran Thien Thanh, Vidmar, T., Vukanac, I., and Yang, M. J.: Intercomparison of methods for coincidence summing corrections in gamma-ray spectrometry part II (volume sources), Appl. Radiat. Isotopes, 70, 2112-2118, doi:10.1016/j.apradiso.2012.02.079, 2012.

Madigan, D. J., Baumann, Z., and Fisher, N. S.: Pacific bluefin tuna transport Fukushima-derived radionuclides from Japan to California, P. Natl. Acad. Sci. USA, 109, 9483-9486, doi:10.1073/pnas.1204859109, 2012.

Miyazawa, Y., Masumoto, Y., Varlamov, S. M., Miyama, T., Takigawa, M., Honda, M., and Saino, T.: Inverse estimation of source parameters of oceanic radioactivity dispersion models associated with the Fukushima accident, Biogeosciences, 10, 2349-2363, doi:10.5194/bg-10-2349-2013, 2013.

Nielsen, S. P., Iosjpe, M., and Strand, P.: A Preliminary Assessment of Potential Doses to Man from Radioactive Waste Dumped in the Arctic Sea. Ris $\varnothing-\mathrm{R}-841(\mathrm{EN})$; Ris $\varnothing$ National Laboratory, Roskilde, Denmark, 1995.

Nielsen, S. P.: Radioactive Fallout in Denmark from the Fukushima Accident, http://meeting.helcom.fi/c/document_library/get_file? p_1_id=16324\&folderId=1438116\&name=DLFE-45401.pdf, 2011.

Nielsen, S. P., Lüning, M., Ilus, E., Herrmann, J., Outola, I., Ikäheimonen, T. K., Mattila, J., Kanisch, G., and Osvath, I.: Baltic sea, in: Radionuclides in the environment, edited by: Atwood, D. A., Chichester, Wiley-Interscience, 32 pp., 2010.

Novković, D., Kandić, A., Đurašević, M., Vukanac, I., Milošević, Z., and Nađđerđ, L.: Coincidence summing of X- and $\gamma$-rays in $\gamma$-ray spectrometry. Nucl. Instrum. Meth. A, 578, 207-217, 
doi:10.1016/j.nima.2007.05.199, 2007.

Povinec, P. P., Aoyama, M., Biddulph, D., Breier, R., Buesseler, K., Chang, C. C., Golser, R. Hou, X. L., Ješkovský, M., Jull, A. J. T., Kaizer, J., Nakano, M., Nies, H., Palcsu, L., Papp, L., Pham, M. K., Steier, P., and Zhang, L. Y.: Cesium, iodine and tritium in NW Pacific waters - a comparison of the Fukushima impact with global fallout, Biogeosciences Discuss., 10, 63776416, doi:10.5194/bgd-10-6377-2013, 2013.

Press, W. H. and Teukolsky, S. A., Vetterling, W. T., and Flannery, B. P.: Numerical recipes in FORTRAN, second edn. Cambridge Unversity Press, 1992.

Rowan, D. J and Rasmussen, J. B.: Measuring the bioenergetic cost of fish activity in situ using a globally dispersed radiotracer $\left({ }^{137} \mathrm{Cs}\right)$, Can. J. Fish. Aquat. Sci., 53, 734-745, 1996.

Rowan, D. J. and Rasmussen, J. B.: Reply - Measuring the bioenergetic cost of fish activity in situ using a globally dispersed radiotracer $\left({ }^{137}\right.$ Cs $)$, Can. J. Fish. Aquat. Sci., 54, 1955-1956, 1997.

Siiskonen, T. and Toivonen, H.: A model for fitting peaks induced by fast neutrons in an HPGe detector, Nucl. Instr. Meth. A, 540, 403-411, doi:10.1016/j.nima.2004.11.021, 2005.

Sima, O., Arnold, D., and Dovlete, C.: GESPECOR: a versatile tool in gamma ray spectrometry, J. Radioanal. Nucl. Ch., 248, 359364, 2001.

Smith, J. T.: Modelling the dispersion of radionuclides following short duration releases to rivers. Part II. Uptake by fish, Sci. Total Environ., 368, 502-518, 2006.
Stohl, A., Seibert, P., Wotawa, G., Arnold, D., Burkhart, J. F., Eckhardt, S., Tapia, C., Vargas, A., and Yasunari, T. J.: Xenon133 and caesium-137 releases into the atmosphere from the Fukushima Dai-ichi nuclear power plant: determination of the source term, atmospheric dispersion, and deposition, Atmos. Chem. Phys., 12, 2313-2343, doi:10.5194/acp-12-2313-2012, 2012.

Uher, J., Roach, G., and Tickner, J.: Peak fitting and identification software library for high resolution gamma-ray spectra. Nucl. Instrum. Meth. A, 619, 457-459, doi:10.1016/j.nima.2009.12.086, 2010.

Vidmar, T. and Kanisch, G.: Intrinsic error of the point-source and the LS-curve approximations in treatment of true coincidence summing, Appl. Radiat. Isotopes, 68, 1785-1788, doi:10.1016/j.apradiso.2010.02.016, 2010.

Vidmar, T. and Korun, M.: Calculation of "LS-curves" for coincidence summing corrections in gamma ray spectrometry, Nucl. Instrum. Meth. A, 556, 543-546, doi:10.1016/j.nima.2005.11.052, 2006.

Vivier, A., Manificat, G., Picolo, J.-L., Fleury, S., Mokili, M., and Guo, X.: Decision threshold associated with multiple measurements. Application to the synthesis of the environment monitoring results, Radioprotection, 47, 51-77, doi:10.1051/radiopro/2011153, 2012.

Wang, W.-X., Ke, C., Yu, K. N., Lam, and P. K. S.: Modeling radiocesium bioaccumulation in a marine food chain, Mar. Ecol.-Prog. Ser., 208, 41-50, 2000. 